Type of the Paper (Article)

\title{
Prevalence of Multidrug Resistance Mycobacterium Tuberculosis (MDR-TB)
}

\section{Using GeneXpert Assay in Northern Sudan, How Serious is the situation?}

Sufian Khalid Mohamed Noor ${ }^{1}$, Mohamed Osman Elamin², Ziriab Imad Taha ${ }^{3}$, Mohammed Salah³, Taqwa Anwar ${ }^{3}$, Ahmed A. Osman ${ }^{*}$, Hatim Abdullah Natto².

${ }^{1}$ Faculty of Medicine, Nile Valley University, Sudan.

${ }^{2}$ Faculty of Public Health and Health Informatics, Umm Al-Qura University, Kingdom of Saudi Arabia.

${ }^{3}$ Faculty of Medicine, University of Bahri, Sudan.

* Correspondence: Ahmed A. Osman

Department of Health Education and Promotion, Faculty of Public Health and Health Informatics, Umm Al-Qura University, Kingdom of Saudi Arabia. Tel.: 00966544941248

E-mail: sudanup.ao@gmail.com ORCID: 0000-0002-3022-932X

Abstract: Background: World Health Organization (WHO) estimates that there were 558000 new cases with resistance to Rifampicin, of which $82 \%$ had multidrug-resistant tuberculosis (MDR-TB). Objectives: We aimed to identify the prevalence of MDR-TB in River Nile state, Sudan, and the risk factors contributing to its occurrence. Methods: This was a descriptive cross-sectional hospitalbased study involved 200 specimens taken from patients suspected of having MDR-TB tested using an automated GeneXpert assay. Results: Results of GeneXpert assay showed that the presence of Mycobacterium tuberculosis in $81(40.5 \%)$, and out of 81 positive test results there were $13(16 \%)$ had MDR-TB. Additionally, 7 cases of MDR-TB were previously treated which represented about (53\%) of MDR patients, the remaining 6 MDR-TB patients were new cases and represented (47\%) of MDR-TB patients. Moreover, there were 4 MDR-TB patients who had a history of contact with MDR-TB patients. Conclusion: Prevalence of MDR-TB in River Nile State, Sudan was 16\%, which is greater than WHO estimation for Sudan (10.1\%). The results revealed that the main risk factor to develop MDR-TB was a history of contact with MDR-TB, so adherence to treatment and social awareness about the spread of MDR-TB are crucial preventive measures.

Keywords: GeneXpert; MDR-TB; Prevalence; River Nile State; Sudan

\section{Introduction}

WHO estimated that over 10 million people globally has TB in 2017 and 2018, although the reported number is only 7 million [1,2]. TB is one of the top 10 causes of death worldwide and in recent studies, WHO estimated the incidence of new cases reaching $4.1 \%$ and $19 \%$ of previously treated cases with MDR-TB [3].

TB is one of the public health concerns in Sudan, as it is accounted among countries with higher TB burden in the Eastern Mediterranean Region/World Health Organization (EMR/WHO) [4, 5]. In 2017, there were 21054 cases reported in Sudan [6], and recent WHO reports revealed that tuberculosis-related mortality rate estimated at 25 per 100000 population [3]. Both Rifampin (RIF) and Isoniazid (INH) resistance are reliable markers of MDR-TB [7]. Drug-resistant TB continues to be a global public health concern, with approximately 580,000 cases worldwide and mortality rates higher than most cancers [1, 8-11]. WHO surveillance data estimated 600000MDR-TBcasesand 
deaths of 490000 people with MDR-TB in 2016 [3]. The prevalence of MDR-TB is high in subSaharan Africa, particularly among patients with a history of previous TB treatment [12, 13]. In countries with limited resource such as Sudan, MDR-TB is public health threat due to poor adherence to treatment, delay of treatment, and shortage of diagnostic centres for MDR-TB [14]. MDR-TB is considered the main barrier to the control of TB in humans worldwide [15]. WHO established a list of risk factors that might be associated with the development of MDR-TB [16]. In addition, several studies have identified the risk factors associated with MDR-TB, which include poor adherence to treatment, improper dosage, a short duration of treatment, and inadequate drugs supply [17].

More recently, progress has been made in testing, detecting, and treating MDR-TB resulting in detection of $51 \%$ of patients with bacteriologically confirmed TB for rifampicin resistance [1]. Despite this progress, the number of patients treated in 2017 and 2018 was only one-third (32\%) of approximately 500,000 patients who developed MDR-TB [1,2].

On the other hand, the use of the rapid test GeneXpert MTB/RIF had expanded substantially since 2010 when WHO first recommended its use. The test detects TB and the possible resistance to Rifampicin. The diagnosis with this test can be made within 2 hours, and WHO now recommends usage of the test as an initial diagnostic test in all patients with signs and symptoms of TB [3].

\section{Materials and Methods}

This study was a descriptive cross-sectional hospital-based study conducted in River Nile State, Sudan during the period between March 2018 and October 2018. River Nile State is one of the northern states of Sudan composed of seven localities with an estimated population of 1.472 million. In Atbara locality, there is a diagnostic center with available GeneXpert assay testing facilities. In this study, we included 200 TB patients who were suspected to have MDR-TB during the study period. We used a questionnaire with closed-ended questions as a study tool, which was filled by the principal investigators. The questionnaire contained data about the demographic features of the participants as well as questions regarding the risk factors associated with the occurrence of MDR-TB and the test results of GeneXpert specimens.

Methods of GeneXpert assay

Sample reagent was added in a 2:1 ratio to untreated sputum and in a 3:1 ratio to decontaminate sputum pellets. The additional sample reagent in pellets was necessary to meet the volume requirements for the essay sample. The closed sputum container was manually agitated twice for 15 minutes at room temperature before being transferred of $2 \mathrm{ml}$ of inactivated material to the test cartridge (equivalent to $0.7 \mathrm{ml}$ of untreated sputum or $0.5 \mathrm{ml}$ of decontaminated pellets). Then, the cartridges were inserted into the test platform located in the microscopy room. Test platform (Cepheid, Sunnyvale, CA) is an integrated diagnostic device that performs sample processing and heminested real-time polymerase chain reaction (PCR) analysis in a single hands-free step to diagnose tuberculosis and rapid detection of Rifampicin resistance in the specimens.

Data analysis

Data analysis was performed using SPSS version 21 (IBM Corp., Armonk, NY, USA). Distributions were summarized using descriptive statistics and were presented as frequencies. Categorical variables were summarized as frequencies and proportions (percentages). We used Chi-Square Test with a p-value less than 0.05 was considered significant.

Ethics approval and informed consent 
This study was performed in line with the principles of the Declaration of Helsinki. Approval was granted by the Ethical Committee in River Nile State Univeristy, Sudan (No.: RNV/MED/RE/012/20). Ethical consent to participate in this study was taken from the patients before commencing in the study.

\section{Results}

We enrolled 200 cases that were suspected to have MDR-TB. Results revealed that most of the patients were males 142 (71\%), whereas the females were 58 (29\%). The most common age group was (15-35 years) in 85 (42.5\%) of them and most of the participants 96 (48\%) were residing in the urban areas as shown in Table 1.

Results of the GeneXpert assay showed the presence of mycobacterium tuberculosis in 81 (40.5\%) of total patients, while the remaining cases 119 (59.5\%) were not detected mycobacterium tuberculosis. Out of 81 positive results, 13 (6.5\%) of them had Rifampicin resistant MDR-TB, while the remaining 68 (34\%) had mycobacterium tuberculosis drug-susceptible as shown in Table 2. In this study, we found that $132(66 \%)$ of patients were previously treated with anti-tuberculous drugs, and $68(34 \%)$ of them had not previous treatment. Additionally, in patients who had previously been treated with anti-tuberculous drugs; 125 (94.7\%) of them completed their treatment while 7 (5.3\%) of them did not complete it. Out of the previously treated patients, 121 $(91.7 \%)$ of them were improved, while $11(8.3 \%)$ were not improved. Most of the previously treated patients showed features of improvement in the form of complete resolution of symptoms in 77 (63.6\%), sputum convert to negative in 46 (38\%), gain weight, and improve in appetite in $59(48.8 \%)$, while 23 (19\%) of them showed a radiological improvement as shown in Table 3.

The history of contact was identified as the main risk factor associated with the development of MDR-TB (P-value $=0.000)$. Moreover, the history of previous treatment is shown to be a protective measure against MDR-TB $(\mathrm{P}$-value $=0.005)$. Results showed that there was no statistically significant association between HIV infection status and MDR-TB (P-value = 0.6); DM and MDRTB $(\mathrm{P}$-value $=0.4)$ as shown in Table 4 .

Table (1): Distribution of demographic characteristics of the participants $(N=200)$

\begin{tabular}{lcc}
\hline \multicolumn{2}{c}{ Character } & Frequency (\%) \\
\hline \multirow{3}{*}{ Age } & $15-35$ & $85(42.5)$ \\
& $36-55$ & $78(39.0)$ \\
\multirow{3}{*}{ Gender } & $56-75$ & $32(16.0)$ \\
& More than 75 & $5(2.5)$ \\
Residence & Male & $142(71.0)$ \\
& Female & $58(29.0)$ \\
& Urban & $96(48.0)$ \\
\hline
\end{tabular}


Table 2: The distribution of study group according to GeneXpert results $(\mathrm{N}=\mathbf{2 0 0})$.

\begin{tabular}{llll}
\hline GeneXpert & & $\mathbf{N}$ & $\mathbf{\%}$ \\
\hline \multirow{2}{*}{ Positive } & MDR-TB & 13 & 6.5 \\
& Non MDR-TB & 68 & 34 \\
Total positive & & 81 & 40.5 \\
Negative & & 119 & 59.5 \\
Total & & 200 & 100 \\
\hline
\end{tabular}

Table (3) The characteristics of the patients according to their treatment and improvement.

\begin{tabular}{lcc}
\hline Item & & $\mathbf{N}(\mathbf{\%})$ \\
\hline Previously treated with anti-tuberculous drugs $^{*}$ & Yes & $132(66 \%)$ \\
Completed their treatment $^{* *}$ & No & $68(34 \%)$ \\
& Yes & $125(94.7 \%)$ \\
Improved $^{* *}$ & No & $7(5.3 \%)$ \\
& Yes & $121(91.7 \%)$ \\
Complete resolution of symptoms $^{* * *}$ & No & $11(8.3 \%)$ \\
Sputum converted to negative & Yes & $77(63.6 \%)$ \\
Gain weight and improvement in appetite & No & $44(36.4 \%)$ \\
& Yes & $46(38 \%)$ \\
Radiological improvement*** & No & $75(62 \%)$ \\
& Yes & $59(48.8 \%)$ \\
\hline
\end{tabular}

* Out of total patients $(\mathrm{N}=200) .{ }^{* *}$ Out of patients previously treated with anti-tuberculous drugs $(\mathrm{N}=132) .{ }^{* * *}$ Out of Improved patients whom previously treated with anti-tuberculous drugs ( $\mathrm{N}$ $=121$ ). 
Table 4: The association between specific risk factors and development of MDR-TB ( $N=81$ total positive GeneXpert assay).

\begin{tabular}{|c|c|c|c|c|}
\hline \multicolumn{2}{|c|}{ Variable } & \multirow{2}{*}{$\begin{array}{c}\text { MDR-TB } \\
1(33.3 \%)\end{array}$} & \multirow{2}{*}{$\begin{array}{c}\begin{array}{c}\text { Non- } \\
\text { MDR-TB }\end{array} \\
2(66.7 \%)\end{array}$} & \multirow{2}{*}{$\begin{array}{c}\text { P- } \\
\text { value }\end{array}$} \\
\hline Hictory of Diphotoc & Present & & & \\
\hline mellitus & Not present & $12(15.4 \%)$ & $\begin{array}{c}66 \\
(84.6 \%)\end{array}$ & 0.406 \\
\hline \multirow{2}{*}{$\begin{array}{l}\text { History of } \\
\text { infection }\end{array}$} & Present & $0(0 \%)$ & 1 (100\%) & \\
\hline & Not present & $13(16.2 \%)$ & $\begin{array}{c}67 \\
(83.8 \%)\end{array}$ & 0.66 \\
\hline \multirow{2}{*}{$\begin{array}{l}\text { History of previous } \\
\text { treatment }\end{array}$} & Present & $7(10.65 \%)$ & $\begin{array}{c}59 \\
(89.4 \%)\end{array}$ & \multirow[t]{2}{*}{0.005} \\
\hline & Not present & $6(40 \%)$ & $9(60 \%)$ & \\
\hline \multirow[b]{2}{*}{ History of Contact } & Present & $4(80 \%)$ & $1(20 \%)$ & \\
\hline & Not present & $9(11.8 \%)$ & $\begin{array}{c}67 \\
(88.2 \%)\end{array}$ & $<.001$ \\
\hline
\end{tabular}

\section{Discussion}

To our best available knowledge, there were no previous studies conducted in River Nile State about MDR-TB. This study aimed to detect the prevalence of MDR-TB among suspected tuberculous patients.

In this study, the majority of the study population were males, representing near three-quarters, which is close to the result of a similar study that represented 71\% [18]. The leading affected group in our study was the young aged group, most properly because they are the working group and they are more suspected to have pathogenic bacteria.

During the study period, we identified the prevalence of MDR-TB as $16 \%$ in River Nile state, Sudan; which is closer to findings of Nigerian study identified the prevalence of MDR-TB was $14.7 \%$ [19]. The prevalence of MDR-TB in this study is less than that identified in Kassala State, Sudan where the prevalence was (51.7\%) [20] and less than the prevalence rate determined in a meta-analysis study conducted in Ethiopia, which revealed that $2.18 \%$ of the newly diagnosed and $21.07 \%$ of previously treated patients had MDR-TB [21]. On other hand, the prevalence of MDR-TB in this study is more than another study conducted in Sudan showed the prevalence of MDR-TB to be $5 \%$ among new cases and $24 \%$ among previously treated cases [18].

The main identified risk factors associated with the development of MDR-TB was a history of contact with MDR-TB patients $(\mathrm{p}<0.001)$, while the history of previous treatment was identified to be a protective measure against the development of MDR-TB (P-value $=0.005)$, and these findings are in agreement with similar results of a meta-analysis study conducted in Ethiopia using 34 studies among patients with a history of previous treatment [21]. Our findings disagree with the previous study which determines the previous treatment as a risk factor with a risk ratio of 5.23 (95\% CI:2.30-4.60; $\mathrm{p}<0.001)$ for MDR-TB [18]. Defaulting from treatment was also identified as one of the risk factors for the occurrence of MDR-TB [22].

\section{Conclusions}


This section is not mandatory but can be added to the manuscript if the discussion is unusually long or complex.

\section{Patents}

During the study period, the prevalence of MDR-TB among the whole study group was $6.5 \%$ and about $16 \%$ among all positive results (where M. tuberculosis was detected by using GeneXpert assay). The WHO estimation for Sudan in 2002 was 10.1\%, whereas our findings were higher than the WHO estimation. The main risk factors were history of previous treatment and history of contact with MDR-TB patients.

\section{Recommendation}

We encourage early detection and proper management of TB cases, which belief to reduce the risk of transmission. We recommend providing health services that include modern tests to detect the resistant strain at the states level, monitor all cases of MDR-TB, and report any new cases to the federal ministry of health, Sudan besides increasing social awareness about the risk of the spread of MDR-TB and how to combat it to control the increasing number of patients with MDR-TB.

Author Contributions All authors contributed to equally the study conception and design. Sufian K. Noor performed material preparation, data collection, and analysis. Mohammed O. Elamin and Ahmed A. Osman wrote the first draft of the manuscript and all authors commented on previous versions of the manuscript. All authors read and approved the final manuscript.

Funding: This research received no external funding.

Institutional Review Board Statement: The study was conducted according to the guidelines of the Declaration of Helsinki, and approved by Ethical Committee in River Nile State University, Sudan (No.: RNV/MED/RE/012/20).

Informed Consent Statement: Informed consent was obtained from all subjects involved in the study

Data Availability Statement: All data generated or analysed during this study are included in this published article.

Conflicts of Interest: The authors declare no conflict of interest.

\section{References}

1. WHO. Global tuberculosis report executive summary 2019. [cited 2019 Oct 28]. Available from: URL:https://www.who.int/tb/publications/global_report/tb19_Exec_Sum_15October2019.pdf?ua=1.

2. WHO. Global tuberculosis report (full). 2019. [cited 2019 Oct 28]. Available from: URL:https://apps.who.int/iris/bitstream/handle/10665/329368/9789241565714-eng.pdf?ua=1

3. World Health Organization WHO website https: //www .who. int/immunization/diseases/tuberculosis/en/

4. Abdallah TM, Ali AAA. Epidemiology of tuberculosis in Eastern Sudan. Asian Pac J Trop Biomed. 2012;2(12):999-1001.

5. Hassanain, S. A., Edwards, J. K., Venables, E., Ali, E., Adam, K., Hussien, H., \&Elsony, A. (2018). Conflict and tuberculosis in Sudan: a 10-year review of the National Tuberculosis Programme, 2004-2014. Conflict and Health, 12(1). doi:10.1186/s13031-018-0154-0

6. World Health Organization. Global Tuberculosis Report; World Health Organization: Geneva, Switzerland, 2018; Available online: http://apps.who.int/iris/bitstream/handle/10665/274453/9789241565646-eng.pdf?ua=1 (accessed on Jun 12, 2019).

7. X. Chen, B. Wang, W. Yang, F. Kong, C. Li, Z. Sun, et al., Rolling circle amplification for direct detection of rpoB gene mutations in Mycobacterium tuberculosis isolates from clinical specimens, J. Clin. Microbiol. 52 (5) (2014 May) 1540-1548, http://dx.doi.org/10.1128/JCM.00065-14. 
8. Seaworth BJ, Griffith DE. Therapy of Multidrug-Resistant and Extensively Drug-Resistant Tuberculosis. Microbiol Spectr. 2017;5(2).

9. Dheda K, Chang KC, Guglielmetti L, et al. Clinical management of adults and children with multidrug-resistant and extensively drug-resistant tuberculosis. Clin Microbiol Infect. 2017;23(3):131-140.

10. Kapata N, Grobusch MP, Chongwe G, et al. Outcomes of multidrug-resistant tuberculosis in Zambia: a cohort analysis. Infection. 2017;45(6):831-839.

11. WHO. GLOBAL TUBERCULOSIS REPORT. 2016. [cited 2019 Jun 1]. Available from URL:http://apps.who.int/iris/bitstream/10665/250441/1/9789241565394-eng.pdf?ua=1

12. Berhan A, Berhan Y, Yizengaw D. A meta-analysis of drug-resistant tuberculosis in Sub-Saharan Africa: how strongly associated with previous treatment and HIV co-infection?. Ethiopian Journal of health sciences. 2013; 23(3): 271-282.

13. Musa BM, Adamu AL, Galadanci NA, Zubayr B, Odoh CN, Ali yu MH. Trends in prevalence of multidrug-resistant tuberculosis in sub-Saharan Africa: a systematic review and meta-analysis. PLoS One 2017;12:e0185105.

14. World Health Organization (WHO), Multidrug and extensively drug-resistant TB (M/XDR-TB): Global report on surveillance and response. Geneva, Switzerland; WHO Press; 2010. Available from: http://www.who.int/tb/publications/global_report/en/

15. Goble M, Iseman MD, Madsen LA, Waite D, Ackerson L, Horsburgh CR Jr. Treatment of 171 patients with pulmonary tuberculosis resistant to isoniazid and rifampin. N Engl J Med 1993;328:527-532.

16. World Health Organization. Companion handbook to the WHO guidelines for the programmatic management of drug-resistant tuberculosis; 2014 [cited 2018 Sep 26]. Available from: https://www.who.int/tb/publications/pmdt_companionhandbook/en/.

17. Günther G, van Leth F, Alexandru S, Altet N, Avsar K, Bang D, et al. Multidrug-resistant tuberculosis in Europe, 2010-2011. Emerg Infect Dis 2015;21:409-416.

18. Stosic M, Vukovic D, Babic D, Antonijevic G, Foley KL, Vujcic I, et al. Risk factors for multidrugresistant tuberculosis among tuberculosis patients in Serbia: A case-control study. BMC Public Health. 2018;18(1):1-8.

19. Girum T, Muktar E, Lentiro K, Wondiye H, Shewangizaw M. Epidemiology of multidrug-resistant tuberculosis (MDR-TB) in Ethiopia: A systematic review and meta-analysis of the prevalence, determinants and treatment outcome. Trop Dis Travel Med Vaccines. 2018;4(1):1-12.

20. Sharaf Eldin GS, Fadl-Elmula I, Ali MS, Ali AB, Salih ALGA, Mallard K, et al. Tuberculosis in Sudan: A study of Mycobacterium tuberculosis strain genotype and susceptibility to anti-tuberculosis drugs. BMC Infect Dis. 2011;11(July).

21. Abdul-Aziz AA, Elhassan MM, Abdulsalam SA, Mohammed EO, Hamid ME. Multidrug resistance tuberculosis (MDR-TB) in Kassala State, Eastern Sudan. Trop Doct. 2013;43(2):66-70.

22. Egail A, Ibrahim Mohamed NY, Mohamed Nour EO, Hoffner S, Haile M. Molecular characterization of Mycobacterium tuberculosis isolates from pulmonary tuberculosis patients in Khartoum, Sudan. Int J Mycobacterial. 2018 Jul-Sep;7(3):236-241. doi: 10.4103/ijmy.ijmy_82_18. PMID: 30198502. 